Çukurova Üniversitesi Mühendislik Mimarlık Fakültesi Dergisi, 33(2), ss. 165-176, Haziran 2018

Çukurova University Journal of the Faculty of Engineering and Architecture, 33(2), pp. 165-176, June 2018

\title{
Zamansal Baz Uzunluğunun İleri Nesil Yapay Açıklı Radar Uydu Verilerinin Konum Doğruluğu Üzerindeki Etki Analizi
}

\author{
Umut Güneş SEFERCÍK ${ }^{* 1}$
}

Bülent Ecevit Üniversitesi, Geomatik Mühendisliği Bölümü, Zonguldak, Türkiye

Öz

Geliş tarihi: $19.04 .2018 \quad$ Kabul tarihi: 29.06 .2018

Bu çalışmada, 2007 yılından günümüze dek yörüngeye oturtulan ve yeni nesil yapay açıklı radar (SAR) uyduları olarak betimlenen misyonların lideri konumundaki TerraSAR-X (TSX) uydusundan elde edilen dijital yüzey modelleri (DYM) üzerinde zamansal baz uzunluğunun etki analizi gerçekleştirilmiştir. Uyduların aynı bölge üzerinden iki farklı geçişi arasındaki zamansal baz uzunluğu, DYM kalitesi üzerinde doğrudan etkili bir interferometrik parametredir. Çalışmada, bu parametrenin TSX'den üretilen DYM kalitesindeki etkisinin saptanması için aralarında TSX'in en kısa tekrar geçiş süresi olan 1 periyot (11 gün) bulunan bir interferometrik SAR (InSAR) görüntü çifti ile 17 periyot (187 gün) bulunan ikinci bir çiftin karşılaştırmalı doğruluk analizi gerçekleştirilmiştir. Analizlerde, zamansal baz uzunluğu etkisinin direkt olarak kanıtlanabilmesi için sonucu etkiyebilecek diğer tüm parametrelerin eşdeğer olduğu görüntü çiftleri kullanılmıştır. Uygulamalar, Berlin, Almanya üzerinde $20 \mathrm{~km}$ 'lik bir alanı kapsayan 15 alçalış yönünde alınmış yüksek çözünürlüklü spotlight (HS) mod TSX görüntüsü ile gerçekleştirilmiştir. DYM'ler $2 \mathrm{~m}$ grid aralığında üretilmiş olup kalite göstergesi olan mutlak düşey doğruluklar radargrametri tekniği ile elde edilmiş ve yine $2 \mathrm{~m}$ çözünürlüklü bir referans DYM ile model bazlı kıyaslama yöntemi ile analiz edilmiştir. Analizler yerleşim alanı ve orman alanı sınıfları için ayrı ayrı yapılmıştır. Elde edilen sonuçlar, zamansal baz uzunluğunun DYM kalitesi üzerinde beklenenden daha büyük bir etki yarattı̆ğını ve 1 periyotluk minimum zamansal baz uzunluğunda elde edilen DYM'lerin 17 periyotluk süre sonunda elde edilene göre hem yerleşim hem de ormanlık alanda yaklaşık $\% 20$ daha başarılı olduğu gerçeğini ortaya koymuştur.

Anahtar Kelimeler: Zamansal baz uzunluğu, SAR, TSX, DYM, Kalite

\section{Analyzing the Effect of Temporal Baseline on the Geolocation Accuracy of Next Generation Synthetic Aperture Radar Data}

\begin{abstract}
In this study, the effect of temporal baseline on the geolocation accuracy of digital surface models (DSM) derived from TerraSAR-X (TSX) which is the leader of next generation synthetic aperture radar (SAR) missions was throughly analyzed. The temporal baseline, obtained by two different passes of the satellites from the same region, is one of the most effective interferometric parameters on the final DSM quality. In the study, to assess the influence of this parameter on generated TSX DSMs' quality, the comparisonbased analysis of two interferometric SAR (InSAR) image pairs which have the minimum repeat-cycle (11 days) and 17 cycles (187 days) were performed. In the analysis, to demonstrate the effect of temporal baseline clearly, the InSAR-pairs which have same parameters except temporal baseline were preferred. The applications were realized over $20 \mathrm{~km}^{2}$ in Berlin, Germany utilizing 15 descending orbit high
\end{abstract}

*Sorumlu yazar (Corresponding author): Umut Güneş SEFERCIK, sefercik@beun.edu.tr 

Analizi

resolution spotlight mode TSX imagery. The DSMs were generated in $2 \mathrm{~m}$ grid spacing and the vertical absolute accuracies were achieved by model-to-model based comparison with a radargrammetric reference DSM which have also $2 \mathrm{~m}$ original grid spacing. The analysis were performed separately for urban and forest areas. The results demonstrated that the influence of temporal baseline on the DSM quality is much more than expected. The DSM derived from first InSAR-pair (1 cycle) has $20 \%$ better vertical absolute accuracy both for urban and forest land forms in comparison with the InSAR-pair which has longer temporal baseline (17 cycles).

Keywords: Temporal baseline, SAR, TSX, DSM, Quality

\section{GİRİş}

Son y1llarda uzay kaynaklı uzaktan algılama teknolojileri başta haritacılık olmak üzere tarımdan ormancılığa, jeolojiden arkeolojiye, şehir bölge planlamadan Ülke savunmasına kadar uzanan geniş bir yelpazede sıklıkla kullanılmaya başlanmıştır. Uzay kaynaklı uzaktan algılama, pasif ve aktif olmak üzere iki temel prensipte ele alınmaktadır. 1999 yılında, pasif algılamanın temsilcileri olan optik uydu teknolojilerinde bir devrim yaşanmış ve $1 \mathrm{~m}$ yer örnekleme kabiliyetine sahip ilk yüksek çözünürlüklü ticari yer gözlem uydusu IKONOS yörüngesine oturtulmuştur. Optik uydu teknolojilerinde o günlerde başlayan teknolojik devrim günümüze dek devam etmiş ve şuan yörüngede bulunan Worldview-4 uydusu sayesinde yer örnekleme aralığ $0,3 \mathrm{~m}$ seviyesine kadar ulaşmıştır. Aktif görüntüleme temsilcisi SAR uydularında ise devrim, 2007 y1lında bu çalışmanın da konusunu teşkil eden ileri nesil SAR uydusu TerraSAR-X (TSX) liderliğinde yaşanmış [1] ve yer örnekleme aralığı $1 \mathrm{~m}$ seviyesine ulaşmıştır. SAR görüntüleme, hava koşullarından ve güneşten bağımsız enerji üretimi sayesinde gece-gündüz farkından etkilenmeyen teknolojik bir uzaktan algılama yöntemidir. Buna ek olarak, yeni nesil SAR uydularının en güçlü özelliklerinden biri yeryüzünün ihtiyaç duyulan her alanında üç boyutlu dijital yüzey modeli (DYM) üretebilme olanağ1 sunan interferometrik SAR (InSAR) teknolojisine uygun veri üretmeleridir. DYM, yeryüzeyini tüm doğal ve insan yapısı oluşumları içerecek şekilde, $X, Y$ planimetrik koordinatlar ve $\mathrm{Z}$ yükseklikleri ile üç boyutlu olarak modelleyen uzaktan algılama ürünüdür. DYM'ler, uzaktan algılama verileri ile üretilen ilk modeller olup filtrelenmeleri sonucunda, çıplak yeryüzeyi tasviri yapan dijital arazi ve yükseklik modelleri elde edilir. DYM'ler, başta haritalama, şehir bölge planlama, felaket izleme ve yönetimi, coğrafi bilgi sistemleri (GIS), ormancılık ve tarım olmak üzere çeşitli meslek disiplinlerinde yoğun şekilde kullanılmaktadır [2-8]. Bu yoğun talep nedeniyle, günümüze dek birçok DYM üretim tekniği geliştirilmiştir. SAR uydu bazlı verilerden DYM üretimi için en çok tercih edilen yöntemlerden biri InSAR'dir. Bu teknikte, DYM, en az iki SAR görüntüsünden oluşan çiftin geometrik parametreleri kullanılarak bir matematik model ile yaratılır. Bu çift, SAR uydusunun aynı alan üzerinden tek geçişi ya da tekrarlı geçişi ile elde edilir. Tek geçişli InSAR geometrisi iki şekilde sağlanmaktadır. İlk tip, Shuttle Radar Topography Mission (SRTM)'de olduğu gibi uydu platformunun gövde kısmına gönderici ve alıc1 antenler ve platforma monteli sabit bir direğin ucuna yalnızca alıcı özellikte antenler yerleştirilmesi ile gerçekleşir. SRTM'de direk boyu 60m'dir ve bu sabit baz sayesinde aynı bölgeye farklı bakış açılarından eşzamanlı çoklu bakış yapılması sağlanmaktadır. Diğer yöntemde ise senkronize hareket eden iki yada daha fazla uydu ile sürekli bilinen bazlarda eşzamanlı ve yine farklı bakış açılarından aynı bölgeye ilişkin çoklu görüntüleme söz konusudur. $\mathrm{Bu}$ tipe en uygun örneklerden biri TSX ile helix (helezon) geometride senkronize hareket eden TanDEM-X ikiz uydusu ile elde edilen geometridir $[9,10]$. Tek geçişli InSAR yönteminde SAR sinyalleri atmosferde çok benzer yollar izlemektedir ve atmosferik korelasyonsuzluk, ihmal edilebilecek kadar minimal boyuttadır. Sağladığı birçok avantaja rağmen tek geçişli InSAR tekniği, SAR anten pozisyonları arasındaki kısa bazlardan kaynaklanan görüntüleme geometrisi sınırlamaları yaşamaktadır. 
İnterferometrik DYM'lerin büyük bölümü, SAR anteninin en az iki pozisyonu arasında zamansal baz uzunluğu içeren tekrarlı (çoklu) geçiş tekniği ile elde edilen verilerden üretilir. Buna ek olarak, üç boyutlu yüzey deformasyonu haritaları, tekrarlı SAR görüntülerine dayanmaktadır [11-13]. Tekrarlı geçiş birçok uygulama için yararlı veriler üretirken, oluşan zamansal baz uzunluğu, su buharı, yağışlar, rüzgar vb. mevsimsel etkilerden kaynaklı atmosferik korelasyonsuzluğa bağlı olarak InSAR çifleri arasındaki uyumun azalmasına sebep olabilmektedir [14].

Literatürde, çok zamanlı SAR görüntülemesi üzerine bir çok çalışma yapılmış olmasına karşın zamansal baz uzunluğuna bağlı konum doğruluğu değişimi üzerine kapsamlı bir çalışma yapılmadığı belirlenmiştir. $\mathrm{Bu}$ çalışmanın amacı interferometrik DYM'lerin konum doğruluğu üzerinde zamansal baz uzunluğunun olumsuz etkisini, örnek bir araştırma ile kanıtlamaktır. Uygulamada, Berlin, Almanya'yı kapsayan, 11 gün ve 187 gün zamansal baz uzunluğuna sahip interferometriye uygun TSX yüksek çözünürlüklü Spotlight (HS) InSAR çiftlerinden, $2 \mathrm{~m}$ grid aralıklı iki farklı interferometrik DYM üretilmiş ve radargrametri ile elde edilmiş yine $2 \mathrm{~m}$ gridli bir referans DYM ile model bazlı karşılaştıma yaklaşımı ile doğrulukları analiz edilmiştir.

Makale şu şekilde düzenlenmiştir; çalışma alanı ve kullanılan materyaller hakkında bilgiler 2. Bölüm'de yer almaktadır. DYM üretimi ve doğruluk hesaplamaları metodolojisi, 3. Bölüm'de açıklanmaktadır. Elde edilen bulguların sunulduğu 4. Bölüm'ü makalenin sonucu takip etmektedir.

\section{2. ÇALIŞMA ALANI VE KULLANILAN MATERYELLER}

Berlin, Almanya'nın 16 eyaletinden biri ve 3,4 milyon nüfuslu başkentidir. Şehirde, interferometriye elverişli TSX HS görüntülerinin ve Joanneum Araştırma Enstitüsü (Avusturya) tarafından üretilmiş referans DYM'nin sınırları göz önünde tutularak, $5 \mathrm{~km}$ x 4 km $\left(20 \mathrm{~km}^{2}\right)^{\prime}$ lik bir çalışma alanı belirlenmiştir (Şekil 1). Çalışma alanında, yerleşim ve orman olmak üzere iki ana arazi örtüsü hakim olmakla beraber ortometrik yükseklikler deniz seviyesi ile $200 \mathrm{~m}$ arasında değişmektedir.

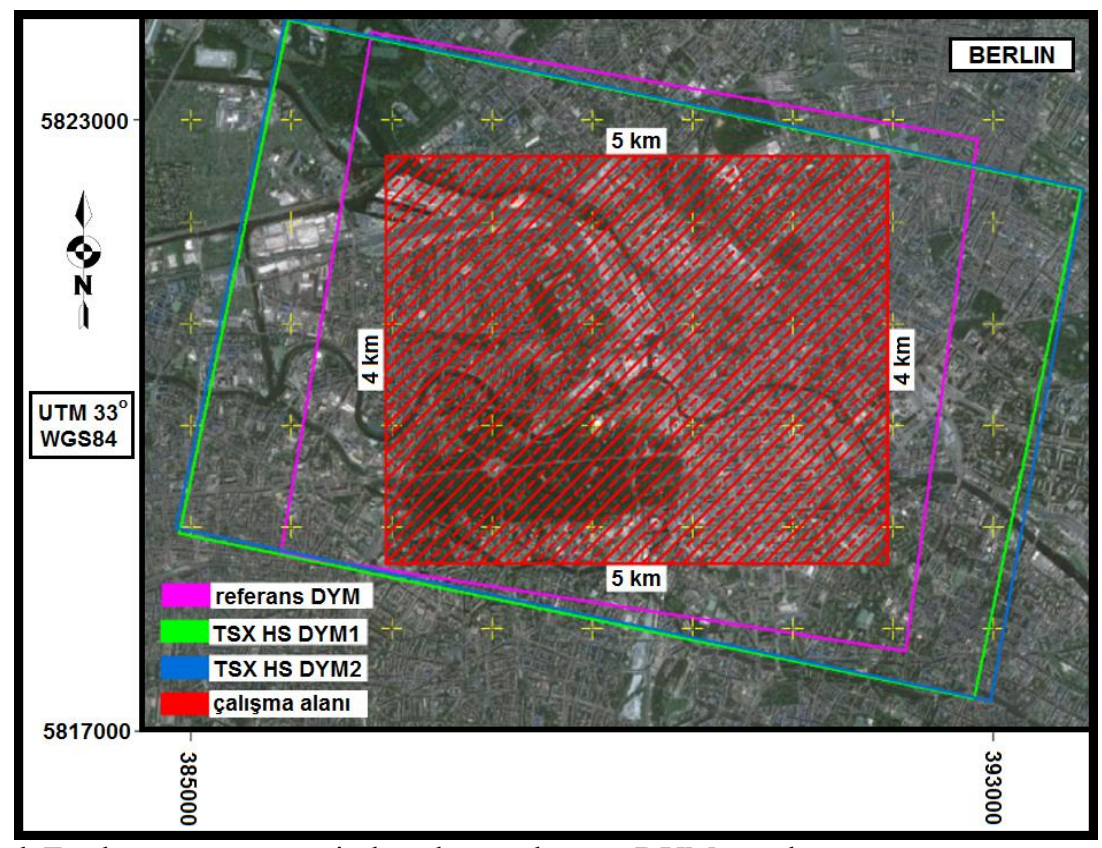

Şekil 1. GoogleEarth görüntüsü üzerinde çalışma alanı ve DYM sınırları 

Analizi

Berlin'in çalışma alanı olarak seçilmesindeki en önemli sebeplerinden biri de Alman Havacılık ve Uzay Merkezi (DLR) tarafından desteklenen ve Ülkemiz adına içinde yer aldığımız LAN0634 kodlu çok uluslu proje kapsamında çok sayıda TSX HS görüntüsünün ücretsiz olarak sağlanmış olmasıdır. Proje dahilinde, Berlin Metropol alanında, sırasıyla SPOT028A ve SPOT042D 1şın çerçevelerinde, 25 yükseliş ve 15 alçalış yörüngesinde elde edilmiş olmak üzere toplam 40 adet TSX HS SAR görüntüsü mevcuttur. $\mathrm{Bu}$ çalışmada, alçalış yörüngesinde alınmış görüntülerin tamamı değerlendirilmiş ve çalışmanın amacına en uygun InSAR çiftleri kullanılmıştır.

TSX uydusunun aynı bölge üzerinden tekrar geçiş periyotu (döngüsü) 11 gündür. $\mathrm{Bu}$ noktadan hareketle ilk InSAR çifti (master-slave) zamansal baz uzunluğu 11 gün olan çiftler arasından seçilmiştir. DYM'nin düşey doğruluğu üzerinde, zamansal baz uzunluğuna bağlı mevsimsel etkilerin tesirini en açık şekilde gösterebilmek hedefiyle, ikinci çiftin master görüntüsü birinci ile aynı seçilmiş, slave görüntü ise yaklaşık 6 aylık zamansal baz uzunluğu (17 döngü) bulunan bir görüntü olarak tayin edilmiştir. Görüntü seçimleri yapılırken, çalışmanın amaçlarına en uygun InSAR çiftini belirlemek için, tüm aday görüntü çiftlerinin eş-kayıt işlemi yapılmış ve baz uzunluğu parametreleri ayrı ayrı değerlendirilmiştir. En elverişli InSAR çiftlerini seçerken, benzer baz parametreleri olan çiftler tercih sebebi olmuştur. Çünkü, ana hedef tüm diğer önemli baz parametrelerini eşdeğer seçip sonuçlar üzerinde zamansal baz uzunluğu dişında hiçbir faktörün etki yaratmamasını sağlamaktır. Böylece zamansal baz uzunluğu etkisi net şekilde ispat edilebilecektir.

Baz parametrelerine ek olarak, kullanılan görüntülerin polarizasyon modları ve ortalama eğim açılarıda aynıdır. Bu şekilde, interferogram üretilirken benek gürültü filtreleme için kullanılan çoklu bakış etkileride eşdeğer kılınmıştır. Çizelge 1, seçilmiş InSAR çiftlerini ve baz uzunluğu parametrelerini göstermektedir.

Çizelge 1. Seçilen InSAR çiftlerinin özellikleri

\begin{tabular}{|c|c|c|c|c|}
\hline \multirow{2}{*}{ Parametre } & \multicolumn{2}{|c|}{ InSAR çifti 1} & \multicolumn{2}{|c|}{ InSAR çifti 2} \\
\hline & Görüntü 4 & Görüntü 5 & Görüntü 4 & Görüntü 12 \\
\hline Görüntüleme modu & \multicolumn{4}{|c|}{ HS } \\
\hline Çekim zamanı & $10 / 05 / 08$ & $21 / 05 / 08$ & $10 / 05 / 08$ & $13 / 11 / 08$ \\
\hline $\begin{array}{l}\text { Piksel çözünürlüğü } \\
\text { Azimut/Mesafe }\end{array}$ & $\begin{array}{l}0,8713 \\
0,7720\end{array}$ & $\begin{array}{l}0,8713 \\
0,7719\end{array}$ & $\begin{array}{l}0,8713 \\
0,7720\end{array}$ & $\begin{array}{l}0,8713 \\
0,7720\end{array}$ \\
\hline Işın ID & \multicolumn{4}{|c|}{ Spot 042D } \\
\hline Yörünge doğrultusu & \multicolumn{4}{|c|}{ Alçalış } \\
\hline Polarizasyon & \multicolumn{4}{|c|}{ Tekil - VV (düşey düşey) } \\
\hline Eğim açısı $\left(^{\circ}\right)$ & 36,0854 & 36,0903 & 36,0854 & 36,0874 \\
\hline Zamansal baz uzunluğu & \multicolumn{2}{|c|}{11 gün (1 periyot) } & \multicolumn{2}{|c|}{187 gün (17 periyot) } \\
\hline Normal baz uzunluğu (m) & \multicolumn{2}{|c|}{246,924} & \multicolumn{2}{|c|}{221,403} \\
\hline Kritik baz uzunluğu (m) & \multicolumn{2}{|c|}{12628,805} & \multicolumn{2}{|c|}{12628,805} \\
\hline $2 \pi$ belirsizlik yüksekliği (m) & \multicolumn{2}{|c|}{23,177} & \multicolumn{2}{|c|}{25,849} \\
\hline $\begin{array}{l}\text { Mesafe ve Azimut ötelemeleri } \\
\text { (pixel) }\end{array}$ & \multicolumn{2}{|c|}{$426,349 /-38,348$} & \multicolumn{2}{|c|}{$347,033 / 33,599$} \\
\hline Doppler merkez kayıklı̆̆ $(\mathrm{Hz})$ & \multicolumn{2}{|c|}{83,548} & \multicolumn{2}{|c|}{67,191} \\
\hline
\end{tabular}




\section{METODOLOJİ}

\subsection{DYM Üretimi}

Metodoloji, interferometrik işlem adımları takip edilerek TSX HS DYM'lerin üretilmesi ve düşey doğruluk değerlendirilmesi olarak iki ana bölüme ayrılmıştır. İlk bölümde, interferometrik DYM üretim prosedürü, ENVI SarScape 4.3 yazılımı kullanılarak tamamlanmıştır (Şekil 2).

İnterferometrik DYM üretimi metodolojisinde, öncelikle, tüm aday InSAR master ve slave çiftleri yukarıda da vurgulandığı gibi eş-kayıt edilmiş ve baz uzunluğu parametreleri ayrı ayrı hesaplanmıştır.
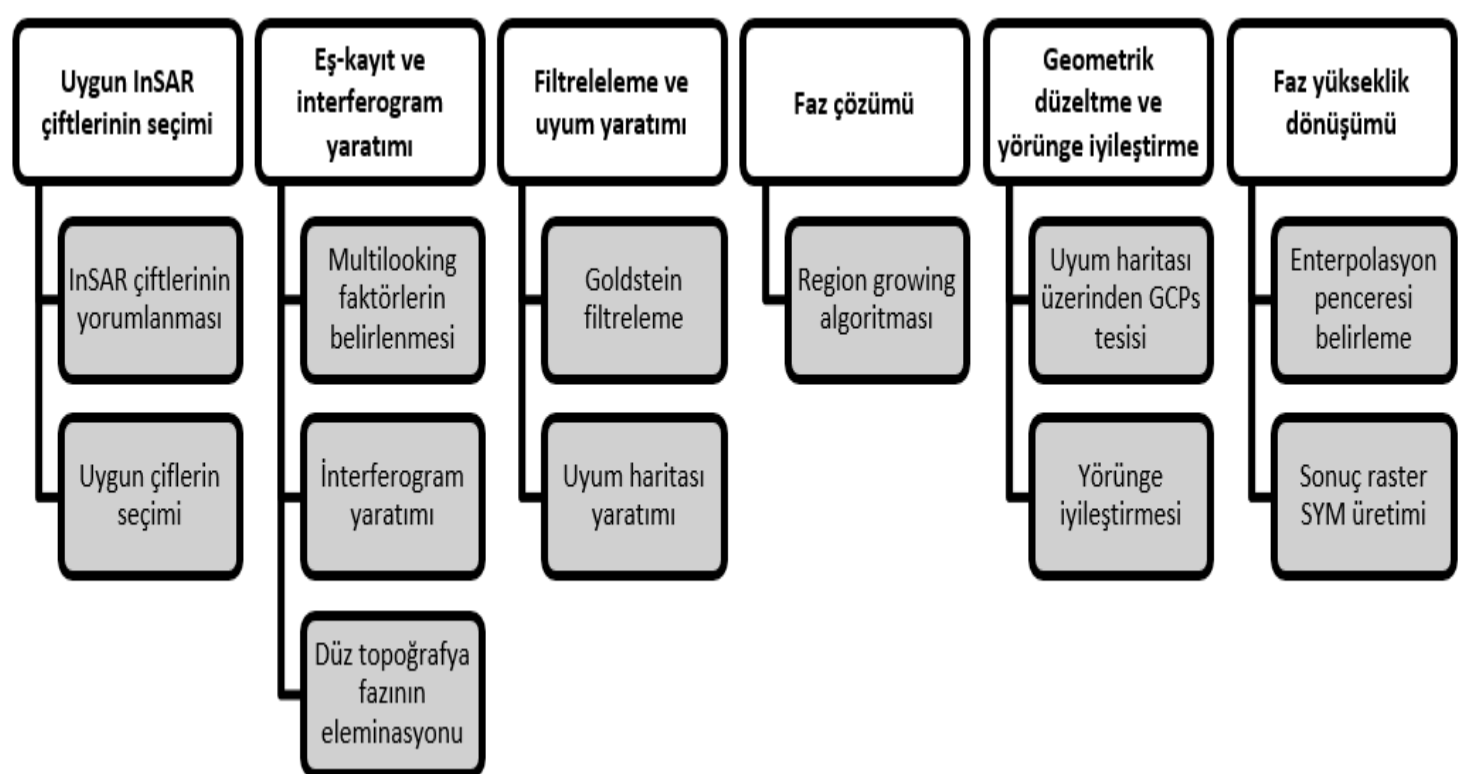

Şekil 2. DYM elde etmek için izlenen interferometrik işlem adımları

En uygun çiftler belirlendikten sonra, interferogramların üretimi aşamasına geçilmiştir. Bilindiği üzere, sinyal gürültü oranı (SNR), sonuç interferometrik ürünlerin kalitesini doğrudan etkileyen en önemli bileşenlerden biridir. $\mathrm{Bu}$ nedenle, gürültü etkisinin interferogram üzerinde en aza indirilmesi amacıyla komşu piksellerin ortalama değerlerini hesaplayarak kare pikseller oluşturma ve bu sayede geometrik çözünürlüğü düşürerek benek gürültüyü azaltma tekniği olan 'multilooking' kullanılmıştır [15]. Multilooking faktörleri eşitlik 1 ve 2 kullanılarak hesaplanmıştır.

$$
\begin{aligned}
& \operatorname{Res}_{\mathrm{r}}=\frac{\operatorname{Res}_{\mathrm{sr}}}{\sin (\theta)} \\
& \left(\operatorname{Res}_{\mathrm{az}} \times \mathrm{m}_{\mathrm{az}}\right) \times\left(\operatorname{Res}_{\mathrm{r}} \times \mathrm{n}_{\mathrm{r}}\right) \cong\left(\operatorname{Res}_{\mathrm{x}}\right) \times\left(\operatorname{Res}_{\mathrm{y}}\right)
\end{aligned}
$$

Eşitliklerde, $\operatorname{Res}_{\mathrm{sr}}, \operatorname{Res}_{\mathrm{r}}, \operatorname{Res}_{\mathrm{az}}$ tek bakışlı kompleks (SLC) SAR görüntülerinin eğik mesafe, mesafe ve azimut piksel büyüklükleridir. $\theta$ eğim açısı, $m_{a z}$ ve $n_{r}$ multilooking faktörleridir. $\operatorname{Res}_{\mathrm{x}}$ ve $\mathrm{Res}_{\mathrm{y}}$ sonuç DYM'nin X ve Y yönlerindeki piksel büyüklüklerini ifade etmektedir.

Ayrıca yer düzlük etkisi de bu aşamada hesaplanmış ve düşük frekanslı bileşenler de interferogramdan ayıklanmıştır. İnterferogram yaratımı ve bazı diğer interferometrik işlem adımlarında doğruluğuna güvenilen mevcut bir DYM, düşük çözünürlüklü topoğrafik fazın büyük bölümünü yok ederek faz çözümünü kolaylaştırmak ve bir yükseklik datumu yaratarak interferogram fazını kalibre etmek gibi amaçlarla kullanılabilmektedir [16]. Bu çalışmada, 

Analizi

bahsedilen amaçlar için Shuttle Radar Topography Mission (SRTM) DYM'si kullanılmıştır.

İnterferogram üretimi ve yer düzlük etkisinin faz bozucu etkisinin eleminasyonu ardından multilooking tekniği ile zayıflatılan benek gürültü etkisini daha da azaltmaya yönelik olarak ana filtreleme uygulaması Goldstein algoritması ile gerçekleştirilmiştir [17].

Eşitlik 3 ve 4'te sunulan bu algoritmada, temel filtreleme mantığı, küçük bir interferogram parçasının Fourier spektrumunun yumuşatılmış mutlak değeri ile bir üstel $\alpha$ 'nın gücüne çarpımıdır. Burada, $\alpha$ adaptif filtereleme parametresini, $u, v$ frekans değişkenlerini, $Z(u, v) \quad$ Fourier spektrumunu, $\sigma_{u, v}^{2}$ etkin band genişliklerini ve $\rho$ eğik mesafeyi ifade etmektedir.

$H(u, v)=|Z(u, v)|^{\alpha}$

$Z(u, v)=\exp \left\{-\frac{\frac{u^{2}}{\sigma_{u}^{2}}-\frac{2 u v}{\sigma_{u} \sigma_{v}}+\frac{u^{2}}{\sigma_{u}^{2}}}{2\left(1-\rho^{2}\right)}\right\}$

Filtrelemeyi takiben, master ve slave InSAR çiftleri arasındaki uyum düzeyini belirlemek için uyum haritaları üretilmiş ve uyum histogramları elde edilmiştir. Uyum düzeyi 0 ve 1 arasında olup, 0 değeri hiç uyum olmadığını 1 ise tamamen uyumlu olduklarını ortaya koymaktadır. Gri renk skalasında tanımlı uyum haritalarında, açık renkli bölgeler yüksek, koyu renkli bölgeler ise gürültü etkisine maruz kalmış düşük korelasyonlu alanları yansitmaktadir.

Interferometrik faz her tam turda $(2 \pi)$ kendini baştan başlatan bir yapıya sahiptir. İteratif olarak baştan başlayan fazın sürekli tek bir faz haline dönüştürülmesi için faz çözümü algoritmasından faydalanılmaktadır. Bu çalışmada, dünya üzerinde Minimum Cost Flow ile beraber en yaygın olarak kullanılan bölgesel büyüme (region growing) [18] algoritmasından yararlanılarak faz çözümü tamamlanmıştır.
Faz değerlerinin yüksekliğe dönüşümü öncesi son geometrik doğrulama yöntemi olan yörüngesel düzeltme için, master ve slave InSAR çiftinin uyum haritaları üzerinden yer kontrol noktaları (YKN) toplanmıştır. YKN seçiminde, uyumu yüksek açık renkli alanlar tercih edilmiş ve YKN atılacak noktada uyum profilleri çizdirilerek 0,9 korelasyon üzeri alanlar tercih sebebi olmuştur.

$\mathrm{Bu}$ noktada, interferometride en çok dikkat edilmesi gereken husus, SAR görüntü distorsiyonları içerisinde en çok karşılaşılanlardan biri olan Layover (ters görüntüleme) etkisidir. Bu etki, radar puls yayılım açısından daha eğimli topoğrafyaların SAR görüntüsünde ters görüntülenmeye sebep olması ile ortaya çıkmakta olup master-slave uyum haritalarında çok açık renk görünerek yüksek uyumlu detay izlenimi vermektedir. Yüksek uyumlu zannedilerek distrosiyonlu bu alanlardan YKN seçilmesi, geometrik doğrulama işleminde hataya neden olmaktadır. $\mathrm{Bu}$ hatadan kaçınmak için YKN atılacak alanda uyum profili çizdirilerek korelasyon miktarı sorgulanması sağlıklı olacaktır. Şekil 3'te, çalışmada analiz edilen iki ayrı InSAR çiftinden elde edilen interferogramlar, uyum haritaları ve uyum haritaları üzerindeki YKN dağılımları görülmektedir.

YKN'lere dayalı geometrik düzeltme ve yörünge iyileştirme işlemlerinin ardından düzeltilmiş olan fazın yükseklik haritasına dönüşümü ile DYM'ler elde edilmiştir. $\mathrm{Bu}$ işlem adımında en önemli parametrelerden biri uygulatılacak enterpolasyon miktarının belirlendiği pencere (radius) seçimidir. Enterpolasyon pencere seçiminde, üretilecek sonuç modelin orjinal grid aralığı ve eldeki verinin mekansal çözünürlüğü göz önünde bulundurulmalıdır. Yüksek enterpolasyon penceresi, verinin mekansal çözünürlügünün düşük olması durumunda topoğrafya üzerindeki çok uzak noktaları işleme dahil ederek sonuç DYM kalitesinin düşük olmasına yani topoğrafyanın aslından farklı tasvirine sebep olabilir. InSAR çifti 1 ve 2 'den üretilen $2 \mathrm{~m}$ gridli DYM'ler sirasiyla TSX DYM1 ve TSX DYM2 olarak adlandırılmıştır. 

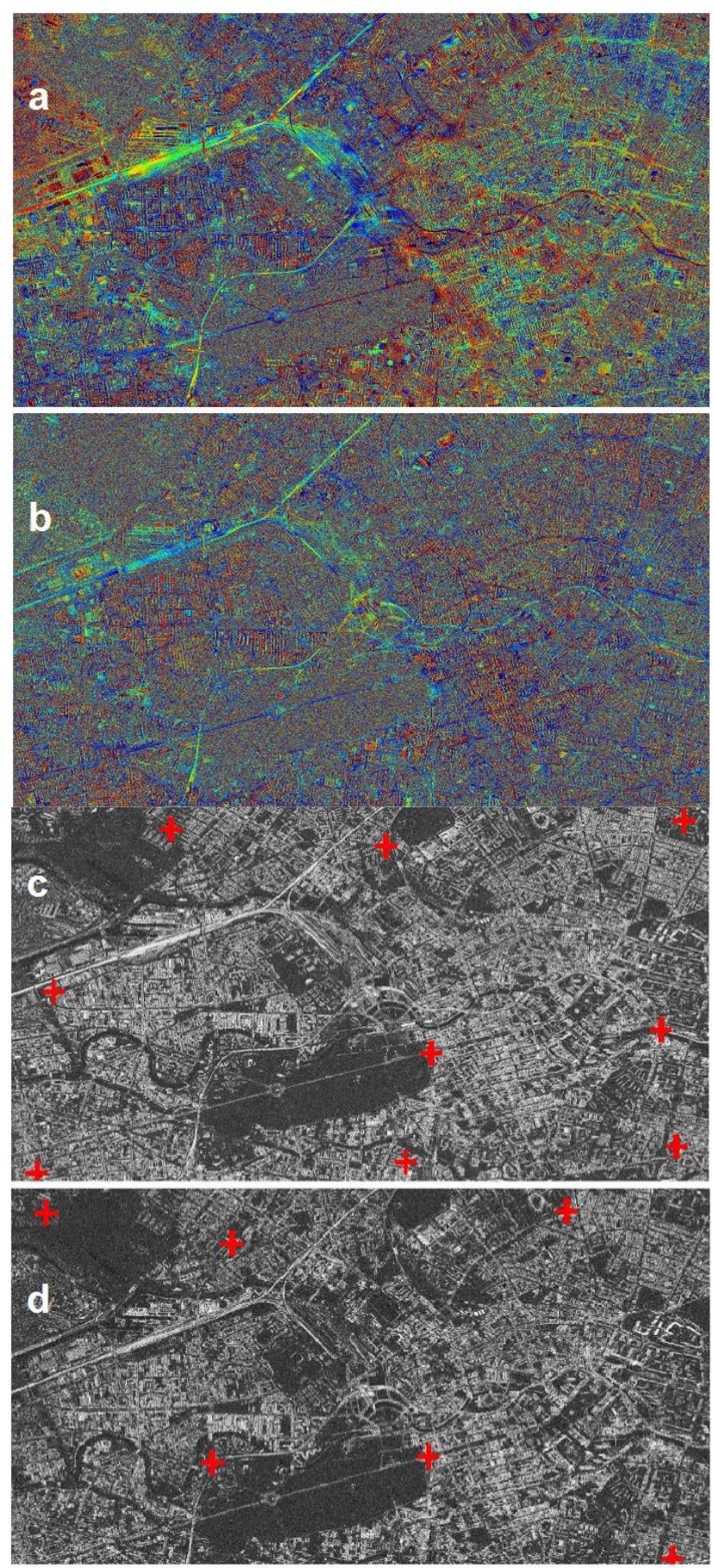

+ YKN

Şekil 3. Üretilen DYM'ler ve uyum haritaları üzerinde YKN dağıllımları; (a) ve (c) InSAR çifti 1'den üretilen interferogram ve uyum haritası, (b) ve (d) InSAR çifti 2'den üretilen interferogram ve uyum haritas 1 


\subsection{DYM Değerlendirmesi}

Uzaktan algılama yöntemlerinden herhangi biriyle üretilen verinin doğruluğu bir referansla kıyaslama yoluyla belirlenmektedir [19]. Bir verinin referans olarak kabul edilebilmesi için aşağıda sunulan ana şartları sağlaması zorunludur;

- Test verisinin analiz edileceği alanı tamamen kapsamalıdır.

- $\quad$ Önemli ölçüde distorsiyon içermemelidir.

- Test verisi ile en az eşit veya daha yüksek orjinal mekansal çözünürlükte olmalıdır.

- $\quad$ Test verisi ile en az eşit kalitede bir ölçme tekniği ile elde edilmiş olmalıdır.

- Test verisinden daha yüksek mutlak yatay ve düşey konum doğruluğuna sahip olmalıdır.

DYM'lerin doğruluk analizlerinde Johanneum Research (Avusturya) tarafindan $2 \mathrm{~m}$ orjinal grid aralığında radargrametrik yöntemle üretilmiş referans DYM ile model-bazlı değerlendirme metodu kullanılmıştır. Model-bazlı değerlendirmeler, raster DYM'yi oluşturan her bir pikselin doğruluk analizlerine dahil edilmesi anlamına gelmektedir. DYM'lerin mutlak düşey doğrulukları, üretilen TSX modelleri ile referans modelde karşılık geldikleri piksellerin yükseklik farklılıklarının standart sapması (SZ) ile belirlenmiştir (Eşitlik 5). Eşitlikte, $\mu$ değeri, piksellerin yükseklik farklarının $(\Delta \mathrm{Z})$ aritmetik ortalamasını, $n$ ise piksel sayısını ifade etmektedir.

$\mathrm{SZ}=\sqrt{\frac{\sum_{\mathrm{i}=1}^{\mathrm{n}}\left(\Delta \mathrm{Z}_{\mathrm{i}}-\mu\right)^{2}}{\mathrm{n}-1}}$

SZ değerine, arazi eğimi $(\alpha)$ etkisi, eğim gruplarından elde edilen $b$ eğim faktörü ile çarpılarak eklenmiş ve arazi eğimine göre değişken mutlak düşey doğruluk elde edilmiştir.

Mutlak düşey doğruluk $=\mathrm{SZ}+\mathrm{b} \times \tan (\alpha)$

Mutlak düşey doğruluğun hatasız hesaplanabilmesi için ön koşul değerlendirilen model ile referans modelin yatay olarak \%100 örtüşmesidir. Aksi halde, Şekil 4'te sunulmuş olan hatalı yatay örtüşmeye $(\Delta \mathrm{D})$ bağlı hatalı yükseklik farkı $(\Delta \mathrm{Z})$ tespiti gerçekleşecektir. Bu durumdan kaçınmak için alan bazlı çarpraz korelasyon metodu kullanılarak modelin referans modelle tam olarak yatay örtüşümü sağlanmıştır. Yatay örtüşüm sağlanması için referans modele kıyasla $X$ ve $Y$ yönlü farklar tespit edilmiş ve giderilmiştir. Aynı zamanda, değerlendirilen modelin SX ve SY yatay konum doğrulukları olarak ortaya konmuştur.

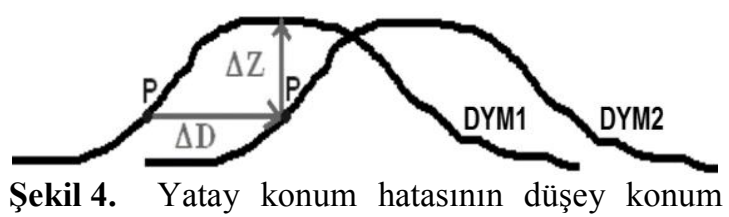
üzerindeki etkisi

\section{BULGULAR}

Tamamlanan interferometrik işlem adımları sonucunda elde edilen DYM'ler Şekil 5a ve 5b'de gösterilmektedir. DYM'lerin her ikisi de Evrensel Enlem Merkatoru (UTM) projeksiyonunda, Dünya Jeodezik Sistemi 1984 (WGS84) datumunda ve $33^{\circ}$ dilim orta meridyenindedir. DYM bulguları göstermektedirki, TSX DYM1'in tasvir yeteneği TSX DYM2'ye nazaran hem çıplak topoğrafyada hem de insan yapısı nesneler için çok daha net ve gürültüsüzdür. $\mathrm{Bu}$ durum, Şekil 5 'te modellerin orta kısmında dikdörtgen içine alınmış yol ağlarının kıyaslaması ile rahatlıkla anlaşılabilir. Hem lineer hem de kurplu yol ağları TSX DYM1'de çok daha açık şekilde tasvir edilmektedir.

Çizelge 2, X ve Y yönlerinde üretilen modellerin elemine edilen yatay konum hatalarını sunmaktadır. Görüldüğü üzere, TSX DYM1'in hem $\mathrm{X}$ hem de $\mathrm{Y}$ yönlerindeki yatay konum hatası TSX DYM2'den düşüktür.

Çizelge 2. Üretilen DYM'lerin yatay konum hatalar1

\begin{tabular}{|c|c|c|c|}
\hline $\begin{array}{c}\text { Referans } \\
\text { DYM }\end{array}$ & $\begin{array}{c}\text { Test } \\
\text { DYM }\end{array}$ & $\begin{array}{c}\text { SX } \\
(\mathrm{cm})\end{array}$ & $\begin{array}{c}\text { SY } \\
(\mathrm{cm})\end{array}$ \\
\hline $\begin{array}{c}\text { Radargrametrik } \\
(2 \mathrm{~m})\end{array}$ & TSX DYM1 (2 m) & -13 & 3,5 \\
\cline { 2 - 4 } & TSX DYM2 (2 m) & -15 & -11 \\
\hline
\end{tabular}



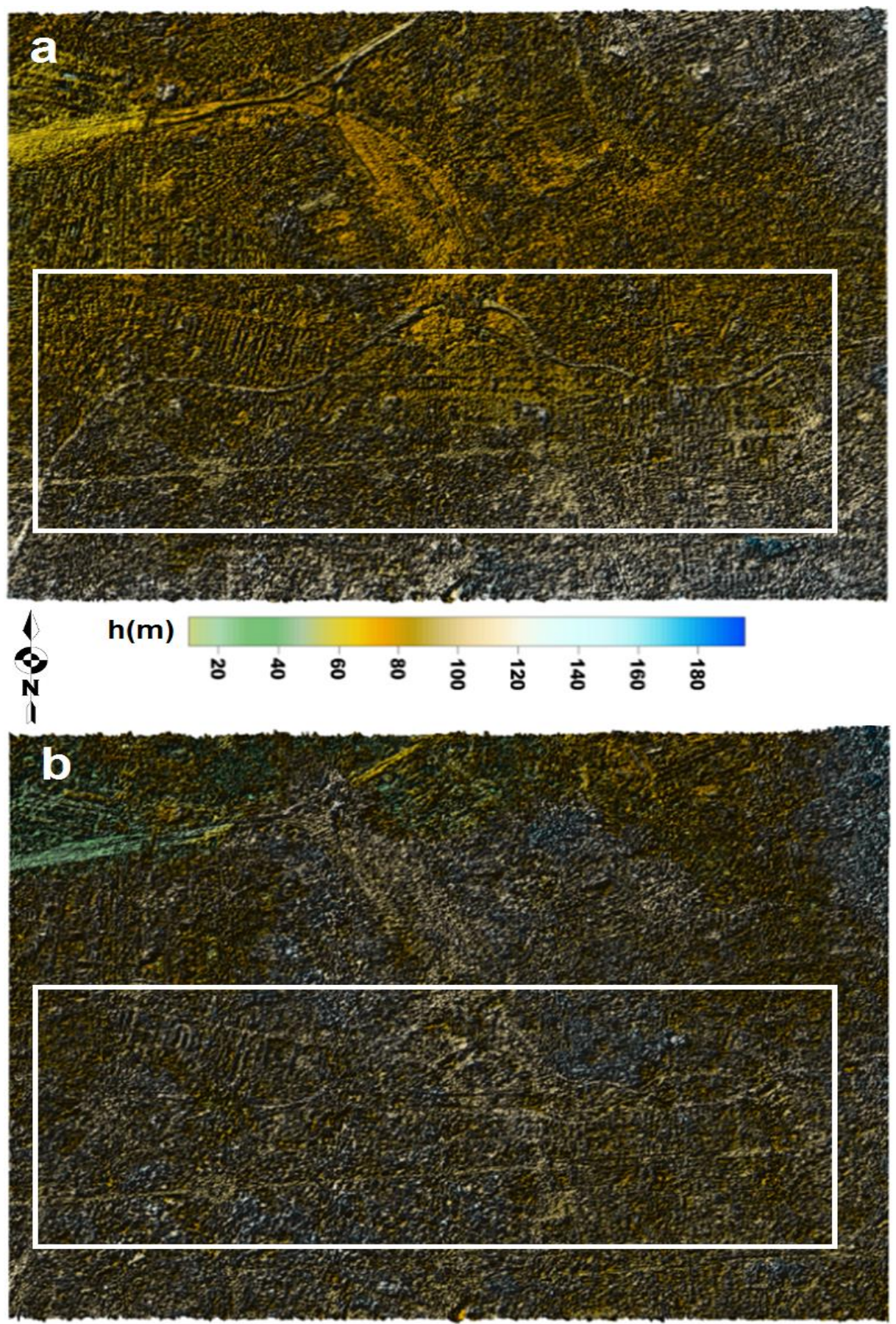

$h(m)$

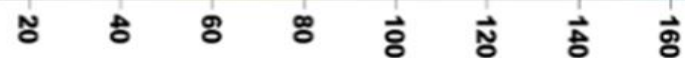

Şekil 5. İnterferometrik DYM'ler; (a) TSX DYM1, (b) TSX DYM2 

Analizi

Üretilen DYM'lerin yatay konum hatalarının eleminasyonu ve tam yatay örtüşme sağlanması ardından elde edilen mutlak düşey konum hataları Çizelge 3'te sunulmuştur. Analizler, hem yerleşim hem de orman alanı için ayrı ayrı yapılmıştır. Yaklaşık beş milyon pikselin dahil olduğu hesaplama sonucunda TSX DYM1'in mutlak düşey konum doğruluğunun TSX DYM2'ye kıyasla hem yerleşim hem de orman alanında yaklaşık 1,5 $\mathrm{m}$ daha iyi seviyede olduğu tespit edilmiştir. Hesaplamalar sırasında, değerlendirilen modeller ile referans model arasındaki piksel bazlı yükseklik farklarına $35 \mathrm{~m}$ eşik değer tanımlanmış ve bu değeri aşan noktalar kaba nokta $(\mathrm{KN})$ tabir edilerek işleme dahil edilmemişlerdir. Hariç tutulan noktaların ihmal edilebilir boyuttaki yüzdeside yine Çizelge 3 'te sunulmuştur.

Çizelge 3. Üretilen modellerin mutlak düşey konum doğruluğu ( $\alpha=$ arazi eğimi)

\begin{tabular}{|c|c|c|c|c|}
\hline $\begin{array}{l}\text { Referans } \\
\text { DYM }\end{array}$ & $\begin{array}{l}\text { Test } \\
\text { DYM }\end{array}$ & $\begin{array}{l}\text { Arazi } \\
\text { sinıfi }\end{array}$ & $\begin{array}{l}\mathrm{SZ} \\
(\mathrm{m})\end{array}$ & $\begin{array}{l}\mathrm{KN} \\
(\%)\end{array}$ \\
\hline \multirow{6}{*}{$\begin{array}{c}\text { Radargra } \\
\text { metrik } \\
(2 \mathrm{~m})\end{array}$} & \multirow{3}{*}{$\begin{array}{c}\text { TSX } \\
\text { DYM1 } \\
(2 \mathrm{~m})\end{array}$} & $\begin{array}{l}\text { Tüm alan } \\
(\% 100)\end{array}$ & $\begin{array}{c}9,31+8,88 \\
x \tan (\alpha)\end{array}$ & 0,10 \\
\hline & & $\begin{array}{c}\text { Yerleşim } \\
\text { alanı } \\
(\% 84,94)\end{array}$ & $\begin{array}{c}9,45+11,19 \\
x \tan (\alpha)\end{array}$ & 0,14 \\
\hline & & $\begin{array}{c}\text { Orman } \\
(\% 15,06)\end{array}$ & $\begin{array}{c}8,63+0,59 \\
x \tan (\alpha)\end{array}$ & 0,01 \\
\hline & \multirow{3}{*}{$\begin{array}{l}\text { TSX } \\
\text { DYM2 } \\
(2 \mathrm{~m})\end{array}$} & $\begin{array}{l}\text { Tüm alan } \\
(\% 100)\end{array}$ & $\begin{array}{c}11,22+0,00 \\
x \tan (\alpha)\end{array}$ & 0,13 \\
\hline & & $\begin{array}{c}\text { Yerleşim } \\
\text { alanı } \\
(\% 84,94)\end{array}$ & $\begin{array}{c}11,42+0,00 \\
x \tan (\alpha)\end{array}$ & 0,18 \\
\hline & & $\begin{array}{c}\text { Orman } \\
(\% 15,06)\end{array}$ & $\begin{array}{c}9,98+0,00 \\
x \tan (\alpha)\end{array}$ & 0,03 \\
\hline
\end{tabular}

Mutlak düşey konum doğruluklarının frekans dağılımları Şekil 6'da yerleşim ve orman alanı için ayrı ayrı sunulmuştur. Grafiklerdeki kırmızı hatlar, sıfır yükseklik farkını $(\Delta Z)$ temsil etmektedir. Yerleşim alanlarında, TSX DYM1'de $\Delta Z$ 'nin tepe noktası yaklaşık sıfırdadır ve dağılım neredeyse simetriktir. Diğer yandan, TSX DYM2'de $\Delta$ Z'nin tepe noktası 5-15 m aralığındadır. Orman alanları göz önünde tutulduğunda, dağılımın tepe noktası hem TSX DYM1 hem 2'de $5 \mathrm{~m}$ civarındadır. TSX
DYM1'in dağ 1 lımı tamamen simetrik iken, TSX DYM2'de $15 \mathrm{~m}$ ile $25 \mathrm{~m}$ arasında dalgalanma mevcuttur. Frekans dağılım sonuçları net olarak göstermiştirki TSX DYM1, referans radargrametrik model ile çok daha uyumludur.

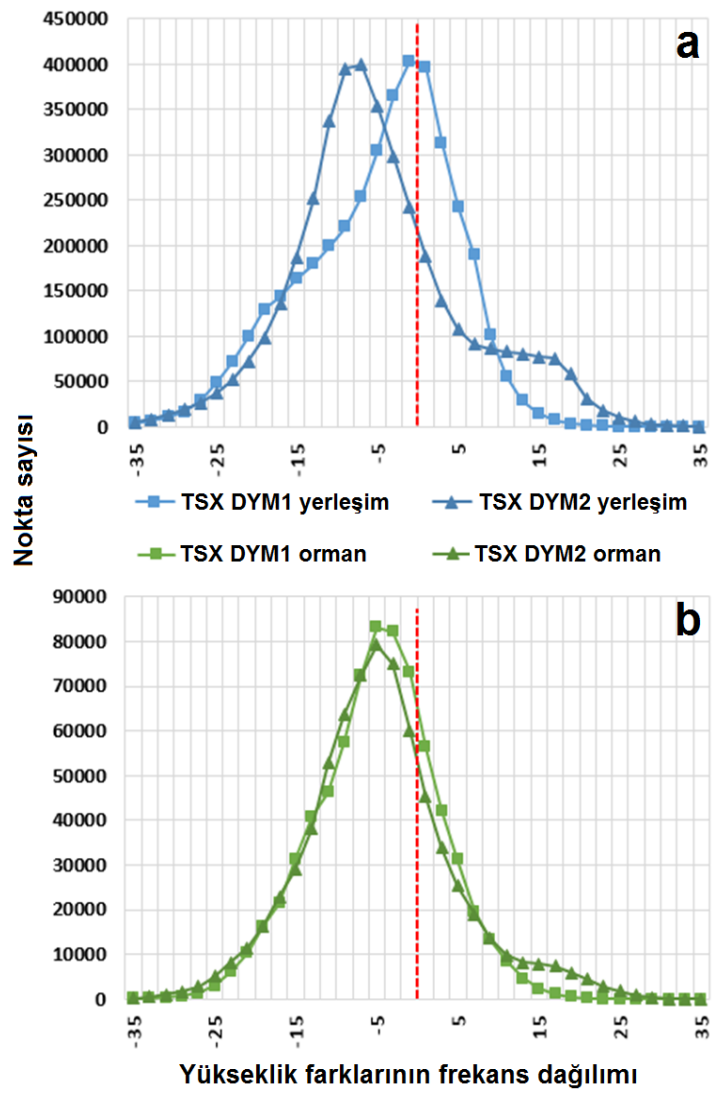

Şekil 6. Yükseklik farklarının frekans dağılımı; (a) yerleşim alanı, (b) orman

Daha önce ifade edildiği üzere, zamansal baz uzunluğu dışında InSAR çiftlerinin özellikleri ve baz uzunluğu parametreleri neredeyse aynıdır. $\mathrm{Bu}$ noktadan hareketle, elde edilen sonuçlar kanıtlamaktadır ki; TSX DYM1 ve 2 arasındaki doğruluk farklarının ana sebebi zamansal baz uzunluğudur. SAR uydu görüntülerinden interferometrik olarak elde edilen sonuç ürünlerin topoğrafik tasvir yeteneğinin maximum seviyede olması isteniyorsa, görüntüleme geometrisi kadar zamansal baz uzunluğundan kaynaklanan mevsimsel ve atmosferik etkilerin de minimal olma gereksinimi vardır. 


\section{SONUÇ}

Makalede, interferometrik yapay açıklıklı radar görüntü çiftleri arasındaki zamansal baz uzunluğunun mekansal çözünürlükte devrim yaratmış ileri nesil radar uydusu TerraSAR-X yüksek çözünürlüklü Spotlight mod verilerinden elde edilen interferometrik dijital yüzey modellerinin mutlak düşey doğrulukları üzerindeki etkisi incelenmiştir. Almanya, Berlin çalışma alanında gerçekleştirilen uygulamada, geniş kentsel ve ormanlık alanda analizler gerçekleştirilmiştir. Araştırmada, 15 adet alçalış yörüngesinde TerraSAR-X görüntüsü kullanılmış ve yapılan baz parametre değerlendirmeleri sonucunda aralarından amaca uygun iki interferometrik yapay açıklıklı radar çifti seçilmiştir. Seçilen çiftlerin zamansal baz uzunlukları sırasıyla 11 gün (1 döngü) ve 187 gündür (17 döngü). Bu şekilde, zamansal baz uzunluğuna bağlı atmosferik ve mevsimsel koşul değişimlerinin üretilen sonuç modeller üzerindeki bozucu etkileri net olarak ortaya konmuştur. Üretilen dijital yüzey modellerinin mutlak düşey doğrulukları, Joanneum Araştırma Enstitüsü tarafından radargrametri yöntemi ile yaratılmış referans bir dijital yüzey modeli ile model bazlı kıyaslama temelinde hesaplanmıştır. Kısa zamansal baz uzunluğuna sahip birinci interferometrik yapay açıklıklı radar çiftinden elde edilen dijital yüzey modelinin mutlak düşey doğruluğu, ikinci interferometrik yapay açıklıklı radar çiftinden elde edilen dijital yüzey modelinden hem yerleşim hem de orman alanı için yaklaşık 1,5 $\mathrm{m}$ daha iyidir. Ayrıca, referans modelden olan yükseklik farklarının frekans dağılım sonuçları, birinci interferometrik yapay açıklıklı radar çiftinden elde edilen dijital yüzey modelinin referans radargrametrik model ile çok daha uyumlu olduğunu göstermiştir. Bu sonuçlar, interferometride görüntü çiftleri arasındaki zamansal baz uzunluğunun atmosferik ve mevsimsel koşulların bozucu etkisi nedeniyle interferometrik dijital yüzey modellerinin mutlak düşey doğrulukları üzerinde belirgin bir etkiye sahip olduğunu ortaya koymuştur. Araştırma sonuçları 1şığında, radar uydu görüntülerinden üç boyutlu yeryüzü modeli üretmek isteyen kullanıcılara, deformasyon yada değişim analizi hedeflenmiyorsa uzun zamansal baza sahip interferometrik görüntü çiftlerinden kaçınmaları önerilmektedir.

\section{TEŞEKKÜR}

Alman Havacılık Merkezi'ne (DLR), LAN0634 kodlu çok uluslu projemize TSX görüntülerini ücretsiz olarak sağladıkları için teşekkürlerimizi sunarız. Ayrıca, proje yöneticimiz Prof. Dr. Uwe SOERGEL'e proje partneri ülkelere bağımsız araştırma ve yayın hakkı verdiği için teşekkür ederiz.

\section{KAYNAKLAR}

1. Roth, A., 2003. TerraSAR-X: A New Perspective for Scientific use of High Resolution Spaceborne SAR Data. $2^{\text {nd }}$ GRSS/ISPRS Joint Workshop on Data Fusion and Remote Sensing over Urban Areas, Berlin.

2. Thompson, J. A., Bell, J. C., Butler, C.A., 2001. Digital Elevation Model Resolution: Effects on Terrain Attribute Calculation and Quantitative Soil-landscape Modeling, Geoderma, 100(1-2), 67-89.

3. Vassilopoulou, S., Hurni, L., Dietrich, V., Baltsavias, E., Pateraki, M., Lagios, E., Parcharidis, I., 2002. Orthophoto Generation using IKONOS Imagery and High-resolution DEM: A Case Study on Volcanic Hazard Monitoring of Nisyros Island (Greece). ISPRS Journal of Photogrammetry and Remote Sensing, 57(1-2), 24-38.

4. Fraser, C.S., 2003. Prospects for Mapping from High-resolution Satellite İmagery, Asian Journal of Geoinformatics, 4(1), 3-10.

5. Schmidt, F., Persson, A., 2003. Comparison of DEM Data Capture and Topographic Wetness Indices, Precision Agriculture, 4(2), 179-192.

6. Navalgund, R.R., Jayaraman, V., Roy, P.S., 2007. Remote Sensing Applications: An Overview, Current Science, 93(12), 1747-1766.

7. Font, M., Amorese, D., Lagarde, J.L., 2010. DEM and GIS Analysis of the Stream Gradient Index to Evaluate Effects of Tectonics: the 
Normandy Intraplate area (NW France), Geomorphology, 119(3-4), 172-180.

8. Sterenczak, K., Kozak, J., 2011. Evaluation of Digital Terrain Models Generated in Forest Conditions from Airborne Laser Scanning Data Acquired in Two Seasons, Scandinavian Journal of Forest Research, 26(4), 374-384.

9. Sefercik, U.G., Jacobsen, K., 2007. Analysis of SRTM Height Models, 5. Türk-Alman Jeodezi Günleri, Teknik Üniversite, Berlin, Almanya, 28-31 Mart, CD, 6.

10.DLR (German Aerospace Center), 2017. TanDEM-X Misyonu Resmi İnternet Sitesi, http://www.dlr.de/hr/en/desktopdefault.aspx/ta bid-2317/, Aralık 2017

11. Ferretti, A., Prati, C., Rocca, F., 1999. Monitoring Terrain Deformations using Multitemporal SAR Images, Fringe'99 Bildiri Kitab1, Liej, Belçika.

12. Wdowinski, S., Hong, S.H., Kim, S.W., Won, J.S., 2010. Small Temporal Baseline Subset Analysis (Stbas): An Insar Technique for Multi-Temporal Water Level Monitoring In Wetlands, Fringe Workshop Bildiri Kitab1, Frascati, İtalya.

13. Jung, H., Alsdorf, D., 2010. Repeat-pass Multitemporal Interferometric SAR Coherence Variations With Amazon Floodplain and Lake Habitats, International Journal of Remote Sensing, 31(4), 881-901.

14. Lau, W.Y., Meng, D., Chang, H.C., Ge, L., Jia, X., Lee, I., 2005. Seasonal Effect on InSAR DEMs, International Symposium on GPS/GNSS, Hong Kong, 8-10 Aralık, 10A-02, CD.

15. Manjunath, D., 2008. Earthquake Interaction Along the Sultandagi-Aksehir Fault Based on InSAR and Coulomb Stres Modeling. University of Missouri, Doktora Tezi, s. 65. Columbia.

16. Seymour M.S., Cumming I.G., 1997. InSAR Terrain Height Estimation using Low-Quality Sparse DEMs, 3. ERS Sempozyumu Bildiri Kitab1, Floransa, İtalya.

17. Goldstein, R.M., Werner, C.L., 1998. Radar Interferogram Filtering for Geophysical Applications, Geophysical Research Letters, 25(21), 4035-4038.
18. Reigber, A., Moreira, J., 1997. Phase Unwrapping By Fusion of Local and globalmethods. Geoscience and Remote Sensing, IGARSS'97 Bildiri Kitab1, 869-871, Singapur.

19. Lin, Q., J.F. Vesecky, H.A., Zebker., 1994. Comparison of Elevation Derived from InSAR Data with DEM over Large Relief Terrain, International Journal of Remote Sensing, 15(9), 1775-1790. 